Installation Technology Transition Program (ITTP)

Facility Degradation and Prediction Models for Sustainment, Restoration, and Modernization (SRM) Planning

Michael N. Grussing

September 2012

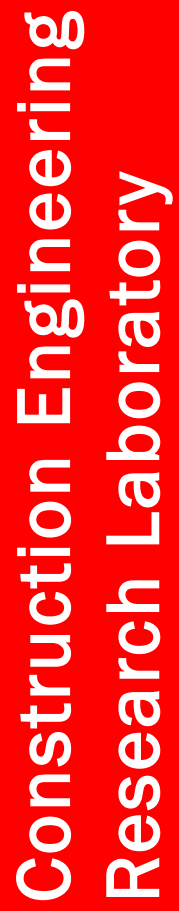





\section{Facility Degradation and Prediction Models for Sustainment, Restoration, and Modernization (SRM) Facility Planning}

Michael N. Grussing

Construction Engineering Research Laboratory

US Army Engineer Research and Development Center

2902 Newmark Drive

Champaign, IL 61822

Final report

Approved for public release; distribution is unlimited.

Prepared for Office of the Assistant Chief of Staff for Installation Management (ACSIM) Arlington, VA 22202

Under Project FY11-02, "Facility Condition Degradation Curves for Prediction Capabilities" 


\section{Abstract}

This report describes the process for integrating the BUILDER Sustainment Management System (SMS) condition life cycle and prediction analysis capabilities with condition assessment information from the Army Installation Status Report for Infrastructure (ISR-I) program to create BUILDER life-cycle condition models. It expands upon previous efforts to integrate the two systems with a common building component and assessment data framework. This framework is based on the ASTM International UniFormat II classification system elements used to integrate the ISR-I facility components for 63 booklets with BUILDER inventory items.

The framework developed in previous work provides the foundation for comprehensive engineering analysis in support of common system functionality between BUILDER and ISR-I. The Army uses ISR-I data and analysis to determine current requirements for facilities. Prediction capabilities allow for better planning for future requirements. This combination provides comprehensive tools and metrics for program-level prioritization of facility management funds for optimal benefit to Army readiness. Prediction model integration was analyzed under the US Army Installation Technology Transition Program (ITTP). The objectives of this demonstration project were to (1) identify a process to transfer ISR-I condition-rating data to BUILDER and (2) use that condition data to compute life-cycle condition metrics.

DISCLAIMER: The contents of this report are not to be used for advertising, publication, or promotional purposes. Citation of trade names does not constitute an official endorsement or approval of the use of such commercial products. All product names and trademarks cited are the property of their respective owners. The findings of this report are not to be construed as an official Department of the Army position unless so designated by other authorized documents. 


\section{Executive Summary}

The Installation Status Report for Infrastructure (ISR-I) and BUILDER Sustainment Management System have complementary purposes and offer considerable synergistic opportunities for tracking and managing the condition of US Army facilities.

The ISR-I is the Army's current process for assessing the condition, performance, and readiness of its facilities. This system is a compilation of facility-related mission and quality criteria organized by component type into 63 booklets. Each booklet represents a major Army facility category, based on mission, encompassing one or more Facility Category Groups (FCGs). Each ISR-I criterion is associated with a color-related qualitative scale (Red, Amber, or Green condition) that is defined with descriptors. The combinations of these ratings determines the general status of a facility or group of facilities at an installation.

The BUILDER SMS is used to effectively manage building requirements at a component level for improved condition and readiness reporting and decision support pertaining to sustainment, restoration, and modernization (SRM) facility investments. It is a web-based enterprise system to facilitate asset recordkeeping, provide analytical capabilities, and offer decision support information for use by management personnel responsible for a large building portfolio. BUILDER makes it possible for facility managers to see critical building condition information in one location through a user-friendly computer interface. BUILDER can be used to perform life-cycle analysis for purposes of work identification at the local installation level, but also can be a source of information for ISR-I in support of higher-level infrastructure reporting.

The purpose of this project is to extend the capabilities of both the ISR-I and BUILDER by more closely linking the two systems in terms of dataexchange capabilities. The focus of this work was integration of BUILDER's life-cycle condition-prediction capabilities with conditionassessment data collected in ISR-I inspections. After ISR-I facility elements were linked to their corresponding BUILDER inventory items using the ASTM UniFormat II classification system, the expected service lives of common facility components were identified. In addition, the ISR-I condi- 
tion color ratings (Green, Amber, Red) can be incorporated into BUILDER's condition-prediction models, providing observation-based data for BUILDER to use in projecting condition life-cycle trends over time.

\section{Benefits}

The Department of Army recognizes the importance of facility condition, as reported in ISR-I, for measuring readiness. ISR-I condition data represents facility quality at the time when the inspection was performed, but the system does not have condition-projection capabilities. Integrating ISR-I large-scale assessment data with BUILDER condition analysis capabilities could help facility planners to more effectively target future SRM requirements and even schedule inspections according to projected need instead of a predefined time interval.

A major advantage of integrating these systems is the use of real-world system inventory data as the basis for analysis instead of modeled information related to generic facility category and mission. Another advantage is that the BUILDER condition index reflects actual observed conditions and reliable estimates of remaining service life for each facility. The resulting benefits to the Army include (1) more actionable information for building managers at the installation level to prioritize local SRM investments and (2) more accurate and auditable information at higher programmatic levels based on actual building configurations, components, and observed conditions.

\section{Costs}

Currently, ISR-I assessments are conducted primarily by Army facility tenants or designated public works officials. Inspections are repeated annually regardless of the condition or importance of the facility or its components. These assessments represent a significant cost in terms of time for facility personnel.

Initial implementation costs associated with BUILDER mainly arise from the collection of facility inventory and condition inspection data. Full BUILDER implementation costs can be substantial, but that cost could be reduced significantly by a direct link to existing ISR-I data. Although ISR-I information is less detailed than needed for a full BUILDER implementation, the effort required to initially populate BUILDER with the relevant ISR-I data is negligible and worth the effort. As more complete and accu- 
rate data become available about the facility inventory (component and material types and quantities), condition assessments, or a project scope, it is input to BUILDER. Installations begin to benefit from BUILDER analytical capabilities without significant costs above the required ISR-I inspection effort.

Also, by applying BUILDER's life-cycle prediction capabilities to ISR-I data, ISR-I re-inspections could be prioritized on the basis of predicted condition and mission-related factors instead of being automatically performed annually. A need-based inspection schedule could significantly reduce the level of installation resources dedicated to periodic ISR-I assessments.

\section{Implementation and maintenance}

With the ISR-I linkage is in place, maintenance of the data in BUILDER is accomplished during the regular ISR-I inspection process by in-house personnel or contractors. As always, proper training is the use of these systems is required to ensure accurate and consistent inspection, data collection, data entry, analysis, and report generation.

\section{Recommendation}

BUILDER and ISR-I are complementary systems with the potential for considerable synergistic opportunities through integration. Using the standardized mapping of common data elements, ISR-I provides the initial data structure (i.e., templates) for BUILDER and generates real-property information needed for a BUILDER implementation. This integrated approach can substantially lower the initial cost of implementing BUILDER at an Army installation.

Basic building information, such as the type, quantity, and year installed for several individual components, are approximated using the templates. When more accurate data are necessary, further facility assessments are required. The increased data collection effort results in more accurate BUILDER prediction models. It is recommended detailed data be collected when a building is approaching consideration for significant upgrade. This approach would provide a phased method for populating and expanding the BUILDER facility information database. 
After the inventory database is established, ISR-I condition rating data should be incorporated into the BUILDER database on a recurring basis to build a condition-assessment history for building components. The condition data from ISR-I are could be merged with other assessment information provided via BUILDER, ROOFER, or other Army-approved systems or methods.

With a condition assessment history for each component and element of a facility, the patented prediction models in BUILDER are used to project facility life-cycle condition and degradation over time, and provide estimates on expected component and system failures over time. This lifecycle condition information provides the basis for developing better shortand long-term facility plans. The BUILDER SMS generates a flexible list of work recommendations for each year based on standards and policies applied across all assets. This ensures that the installation maintains facilities at standard levels based on mission requirements and available funding.

BUILDER can use data from many Army standards systems, and accuracy improves with each additional data source. Future Army standard systems identified for future data exchange include Headquarters Installation Inventory System (HQIIS), Army Mapper, Computerized Maintenance Management Systems (CMMS), and General Fund Enterprise Business System (GFEBS). 


\section{Table of Contents}

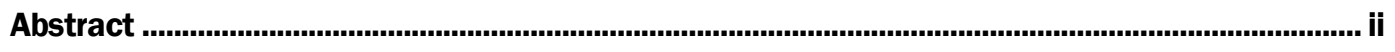

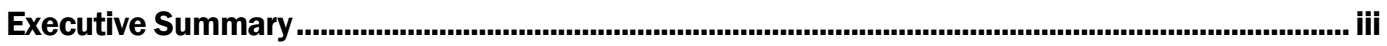

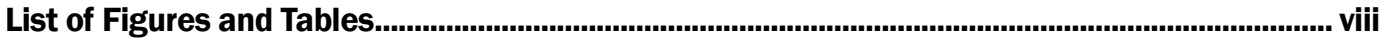

Preface ........................................................................................................................................................ ix

1 Introduction

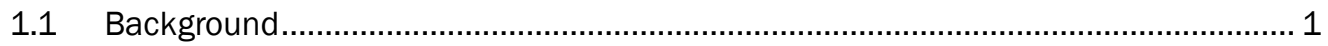

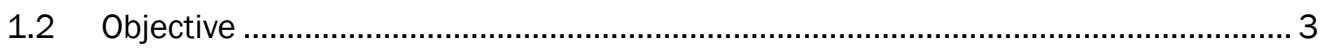

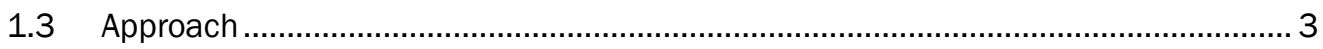

1.4 Mode of technology transfer ........................................................................... 3

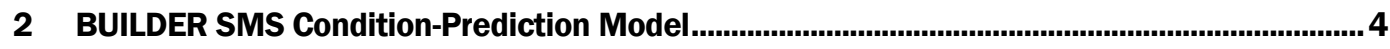

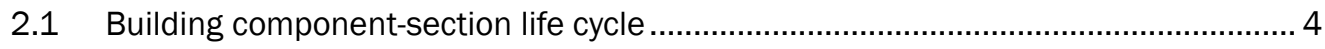

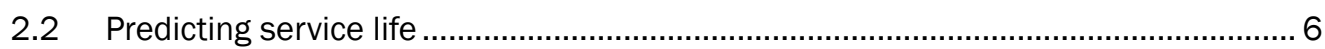

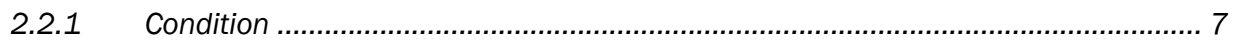

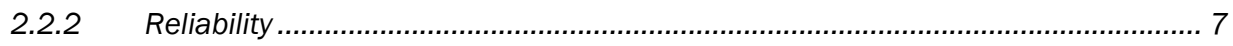

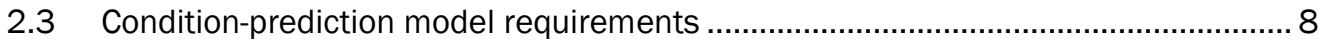

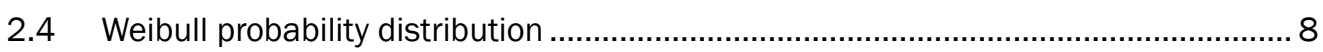

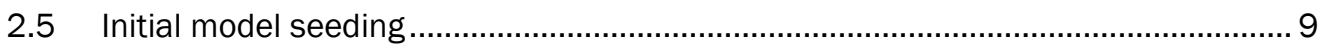

2.6 Calibration with inspection information ........................................................... 10

2.7 Weighting historical inspection data ................................................................ 11

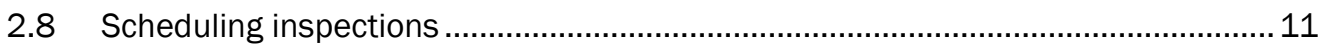

2.9 Calibration when work is performed …............................................................... 12

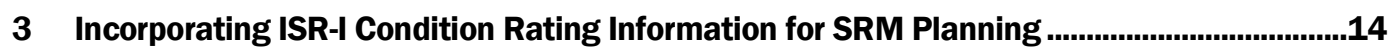

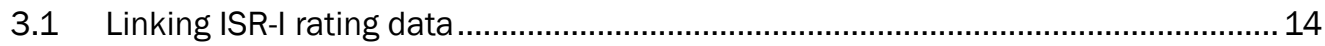

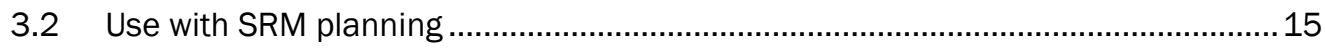

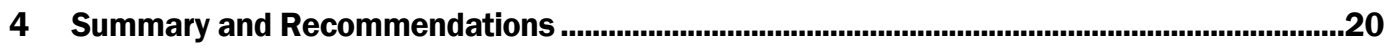

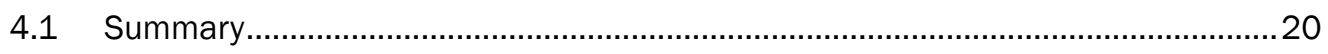

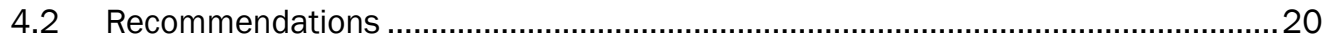

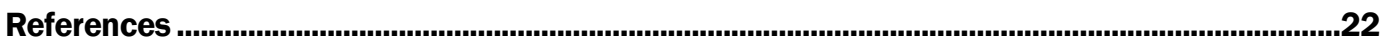

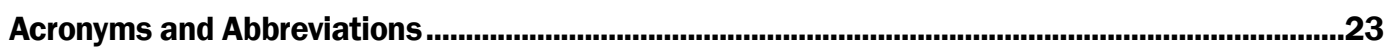

Report Documentation Page 


\section{List of Figures and Tables}

\section{Figures}

Figure 1. Probabilities of failure in year $t$, failure before year $t$, and reliability beyond year $t$. ............. 6

Figure 2. Example initial life-cycle condition trend. ........................................................................

Figure 3. Life-cycle condition trend for component-section after inspection data calibration.

Figure 4. Life-cycle condition trend for component-section after corrective repair............................13

Figure 5. BUILDER condition index mapping to ISR-I rating............................................................14

Figure 6. Adjusted condition trend using ISR-I rating information....................................................15

Figure 7. Facility-level SRM planning information..............................................................................

Figure 8. Rollup performance data from component to system level...............................................17

\section{Tables}

Table 1. Work classification breakdown. 


\section{Preface}

This study was conducted for the US Army Assistant Chief of Staff for Installation Management (ACSIM) under Installation Technology Transition Program (ITTP) Project FY11-02, "Facility Condition Degradation Curves for Prediction Capabilities." The technical reviewer for ACSIM was Philip Columbus, DAIM-ODF.

The work was performed by the Engineering Processes Branch (CF-N) of the Facilities Division (CF), US Army Engineer Research and Development Center - Construction Engineering Research Laboratory (ERDC-CERL). The ITTP Program Manager was Debbie J . Lawrence, CEERD-CV-ZT. At the time of publication, Donald K. Hicks was Chief, CEERD-CF-N; L. Michael Golish was Chief, CEERD-CF; and Martin J . Savoie, CEERD-CV-ZT, was the Technical Director for Installations. The Deputy Director of ERDC-CERL was Dr. Kirankumar Topudurti and the Director was Dr. Ilker Adiguzel.

COL Kevin J. Wilson was the Commander and Executive Director of ERDC, and Dr. J effery P. Holland was the Director. 


\section{Introduction}

\subsection{Background}

A key to successful building asset management is the ability to measure current condition and predict future condition and degradation trends for building components over a specified planning horizon. Developing this capability poses a difficult challenge because of the vast number of different components used in buildings. Each type and variety has a different service life and degradation curve. Condition trends and service lives depend on the amount of investment in preventive and corrective maintenance, including repair, during the component-section ${ }^{1}$ life cycle. These variables make it difficult to accurately project a condition-life-cycle trend for individual component-sections without both periodic inspection and a meaningful condition metric. The purpose of the metric is to provide data for the life-cycle prediction process, but condition data are usually very limited for any given component-section.

This project applied the Weibull probability distribution function used in the BUILDER Sustainment Management System (SMS) for condition prediction to data collected during Army facility inspections. The result is a self-correcting prediction model that uses attribute information collected during both current and past inspections to accurately project the unique life-cycle degradation trend for an individual component-section in a building.

The US Army Engineer Research and Development Center, Construction Engineering Research Laboratory (ERDC-CERL) has developed an SMS approach to building asset management, providing installations with a decision support tool for Sustainment, Restoration, and Modernization (SRM) decisions. The SMS process supports integrated facility management, including inspection, maintenance / repair / recapitalization planning, record keeping, and reporting. It allows facility managers to measure condition changes, manage life-cycle costs, and focus attention and resources on mission-critical assets that provide the best value to the Army.

\footnotetext{
1 This term is explained in section 2.1 .
} 
Implementation of the BUILDER SMS for a building or a group of buildings starts with the creation of building system and component inventory information. These data are stored, managed, and accessed in a central location via the web. Each building component is identified and categorized, and attribute information (e.g., types, materials, quantities, and construction dates) is recorded. The system associates this inventory information with key life-cycle attributes, including replacement costs, expected service lives, and component importance factors. From the initial system component inventory information, the condition life-cycle trend for each component can be projected to model expected degradation over time.

Once the facility component inventory for BUILDER is developed, standardized inspections are conducted on the components to determine a condition index (CI) value that is objective, repeatable, and clearly communicates the general physical health of the asset. The $\mathrm{CI}$ is determined by one of two standardized processes: (1) direct surveys for cursory rating of component condition, and (2) distress surveys for more detailed information about the type of distress, severity, and the amount negatively affecting building components. The two-tiered inspection process allows for transition to more detailed inspection modes as conditions warrant, thus leveling inspection resources appropriately. The list of distresses in a distress survey are finite and directly linked to condition deduct curves developed using building subject matter experts. The collection of this standardized distress information produces a quantitative CI value that models the rating that would be expected from a group of experts. The direct rating procedure also uses standardized condition observations, and results in a CI value correlated to the distress survey procedure results. In addition to deterioration-based performance effects from condition assessments, functionality-based assessments address obsolescence-based impacts on energy costs, user requirements, and code-compliance issues such as accessibility by disabled people. This provides a comprehensive picture of the overall performance - condition and functionality - of the building over time. From this life-cycle condition and functionality assessment information, both short-term and long-range facility plans can be developed. For each year, the BUILDER SMS generates a flexible list of work recommendations based on standards and policies applied across all assets. The goal is to ensure that the installation can maintain facilities at common levels based on mission requirements and funding. 


\subsection{Objective}

The objective of this project was to demonstrate a method that enables BUILDER to generate facility degradation projections based on condition information entered into the SMS and provided by ISR-I surveys. The projections are intended to support both installation-level work planning and strategic-level forecasting analysis.

\subsection{Approach}

The BUILDER condition-prediction model produces a set of facilitydegradation curves based on building age and ISR-I condition data for each Facility Category Group (FCG) documented in the ISR-I booklets. The facility component-level data supports tactical work requirements at the local installation level. It also provides input to the ISR-I model to support condition-prediction and analysis capabilities at the strategic FCG scale.

\subsection{Mode of technology transfer}

The BUILDER SMS is a tool developed through research in asset management, facility investments, and building-condition assessment. This project transfers technology encompassed in the BUILDER SMS to Army installation Departments of Public Works (DPWs) for eventual use in sustaining and managing building asset life cycles. In addition, this project extends BUILDER SMS interoperability to the ISR-I user community.

The results of this project are transferred to the Army through ISR-I data collection and program analysis capabilities. In addition, Army Regulation AR 420-1 specifies the use of Sustainment Management Systems for Army installation public works facility management, including the identification of SRM requirements. BUILDER SMS is an open data architecture to permit free communication with other electronic Army management systems and data repositories, such as ISR-I. 


\section{BUILDER SMS Condition-Prediction Model}

Recent requirements in civil infrastructure asset management have highlighted the need for improved methods, metrics, and tools to support maintenance, repair, and recapitalization decisions for both public and privately owned facilities. The objective of these efforts is to minimize total life-cycle costs while maintaining facility condition and performance above specified levels. Life-cycle costs are optimized by identifying, analyzing, and planning facility repair work in a timely fashion, before the penalty costs due to accelerated facility condition degradation are compounded. This requires knowledge of the relative condition and how the condition degrades over time. For decades, pavement management systems have been available to measure and predict condition for that specific infrastructure domain, but extending the science to building infrastructure management presents a completely new challenge. Currently, the BUILDER SMS software application allows the quantitative calculation of a condition index (CI) value for each component of a building based on an objective condition-survey process. This chapter explains the use of the CI value to track condition trends and project condition and reliability for the vast and diverse array of building components.

\subsection{Building component-section life cycle}

Buildings are complex assets consisting of several major systems and components, and crossing several specialized civil construction disciplines. Because of this, a rigid hierarchical structure, such as the ASTM Uniformat II (U2) standard for building elements classification (ASTM 2002) is required. The U2 standard divides the building first into major assemblies aligned with the construction trade disciplines, then by building systems, and finally by the individual components that make up those systems. Each component is further divided into a component-section to establish component attributes based on material, type, age, and location. For example, a wall (component) may be constructed of masonry or wood. The different materials have different responses to their environment over time, have different service lives, and require different work actions at various stages in their life cycle. As such, the basic management unit for building life-cycle asset management and condition tracking is the component-section. 
Each component-section works interdependently with other componentsections to support the functions of an efficiently operating building. Each component-section ages and deteriorates over time, adversely affecting its performance and reliability. If left in service for long enough, its condition reaches some limit or failure state at which the component-section can no longer serve its intended function sufficiently (Moubry 2002). It also adversely affect the function or condition of other component-sections. This limit state occurs at a typical condition index value (approximately 40) as defined by the building component CI scale. Due to the nature of their function, certain component-sections, such as structural columns, have a service life designed to correspond to the life of the facility. Other component-sections, such as a roof surface, can have a projected lifespan much shorter than the life of the facility. Periodic repair or replacement of the various component-sections is needed to restore condition and performance capabilities as well as that of the building as a whole. Depending on the criticality of the component-section and the consequence of a failure, this corrective action is best performed at or before reaching the failure state.

When a component-section is new, predicting the failure state for a unique component-section in a building is difficult as its true lifespan is rarely known. While a designer or manufacturer can provide a generalized idea of design life for a component-section, actual service life depends greatly on local environmental factors, use and abuse, and levels of routine maintenance accomplished. In addition, for many component-sections, simply defining what constitutes a failure state can sometimes be ambiguous. For instance, does a window component-section fail when the vapor barrier is breached, it is no longer operable, a window pane breaks, or some other criterion? This failure state has a different meaning for different component-sections and to different people. Instead, defining a quantitative failure state based on an objective CI provides a more consistent definition of component failure.

The failure state is rarely the most efficient point when corrective action should be performed. For many component-sections, repair early in the life-cycle extends life and averts expensive damage caused by accelerated degradation later. The "sweet spot" is the point where corrective action is most efficiently applied. Experience with the building component CI metric has shown for a wide variety of components, the repair sweet spot falls 
in the CI equals 70- 80 range. Major repair or replacement penalty costs are avoided by performing repairs at the sweet spot.

\subsection{Predicting service life}

Each building constituent component-section has a finite service life. This service life defines the lifespan for a component-section. Although a building component-section cannot last forever, its service life is extended with proper operation, maintenance, and even repair. Likewise, a componentsection's service life is significantly decreased by environmental factors, abusive operations, or lack of maintenance. These factors cause a wide service life range for a given component-section, so an exact service life is not known at the time of construction or installation. Figure la shows the probability distribution for the time to failure for a hypothetical component-section. The design service life is the time in service when the component-section has the greatest probability of failing, but in actuality the true service life is unique for each component-section. Depending on the service life variance within a unique component-section type, there is probability the actual life could be longer or shorter than the design service life. Design service lives for a wide range of component-sections are published from different sources based on industry estimates. Unfortunately, unlike pavements, little data are available to describe the variances associated with each service life. Because of the vast and diverse array of individual building components, a family analysis approach-common to pavement infrastructure - is not applicable for predicting condition and service life is not applicable.
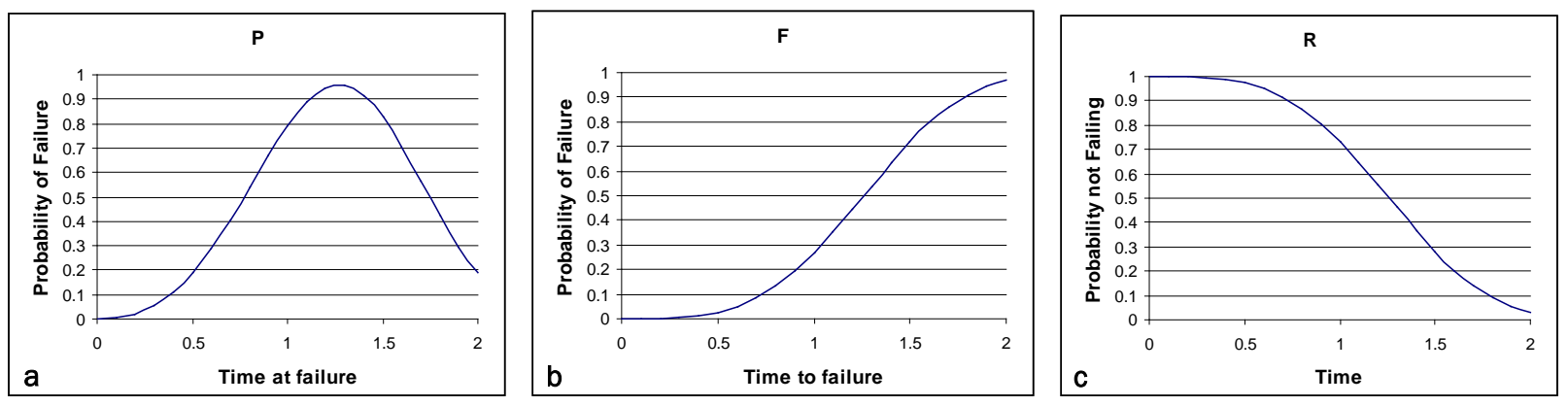

Figure 1. Probabilities of failure in year $t$, failure before year $t$, and reliability beyond year $t$.

The statistical probability of the component-section failing in a given year requires knowledge of the variance in the time from component-section construction or installation to failure. The cumulative failure distribution, Figure 1b, relates the probability the component-section will fail at or be- 
fore a given year. The inverse, Figure 1c, represents the reliability, measured by the probability the component-section will meet or exceed performance standards at a given year in its life cycle.

The prediction model assumes the condition state measured by the CI and the reliability state are proportionally similar. Both are defined below.

\subsubsection{Condition}

The physical condition state indicates the general health of a building component-section. Physical degradation of the component-section due to normal aging, excessive or abusive use, or poor maintenance reduces the component-section's ability to perform as required. In BUILDER, condition is measured in absolute terms by the use of a numerical CI scale that ranges from $0-100$, with 100 defining a defect-free condition. The condition state is reduced when distresses are observed during a structured, objective, and repeatable inspection as prescribed by the BUILDER SMS. These distresses have an adverse affect on the component-section's ability to perform. A CI value is computed through a process that uses deduct values based on distress types, severities, and densities. When a component-section is new, its condition index is assumed to be 100 .

\subsubsection{Reliability}

Reliability is the statistical probability a component-section will meet or exceed performance requirements for a given service life. For most building component-sections, it is a function of the amount of time the component has been in service. In general, condition and reliability are related as follows:

- Condition and reliability are maximum (100) at or near the start of the service life.

- Condition and reliability approach the minimum state (0) asymptotically

- Condition and reliability deteriorate unless corrective action is performed.

- As condition deteriorates, reliability likewise decreases. 


\subsection{Condition-prediction model requirements}

In order to have a robust condition-prediction model, the following methodologies are proposed:

- Model is seeded with reasonable initial assumptions and self-corrects based on collected information.

- Model automatically adjusts the expected service life based on an inspection-generated condition index.

- Model takes into account the inspection date and type when calibrating the prediction trend.

- When repair work is completed, model adjusts the prediction trend.

- Model takes the type of repair work into account when projecting the predicted condition trend.

\subsection{Weibull probability distribution}

The Weibull cumulative probability distribution function is used to model the condition life-cycle curve. The Weibull statistical distribution represents the probability of time to failure of a component-section in service. It has natural boundary conditions that abide by the assumptions discussed above, and takes the shape of a classical condition-deterioration curve. The resulting mathematical condition-prediction model is:

$$
C(t)=a \times e^{-(t / \beta)^{\alpha}}
$$

where

$$
\begin{aligned}
\mathrm{C}(\mathrm{t})= & \text { component-section condition index as a function of time } \\
\mathrm{t}= & \text { time, in years, since component-section was installed or } \\
& \text { constructed } \\
\mathrm{e}= & \text { exponential } \\
\mathrm{a}= & \text { parameter, initial steady state component-section condition } \\
& \quad \text { index } \\
\beta= & \text { parameter, service life adjustment factor } \\
\alpha= & \text { parameter, accelerated deterioration factor. }
\end{aligned}
$$




\subsection{Initial model seeding}

The first step of the self-correcting prediction model process uses initial general assumptions to compute the parameters $a, \alpha$, and $\beta$ to describe the shape of the condition life-cycle trajectory. Initially, when no inspection data exist for the component-section, the only life-cycle information available is the installation or construction date (at which time the assumed CI is 100) and the expected service life (at which time the assumed CI equals some terminal value that indicates the end of service life). The model must be seeded with a degradation factor. Figure 2 illustrates an example with a 30 year service life. The actual degradation factor is set individually for each component-section based on historical trends, if available. If historical data are not available, any reasonable values can be chosen because the model will self-correct once inspection data are collected.

These assumptions initialize the prediction model when no other information exists. Each assumption results in a data point where the x-value is the component-section time in service and the y-value is condition. The three model parameters are then solved using those data points to describe the shape and trajectory of the component-section life-cycle curve.

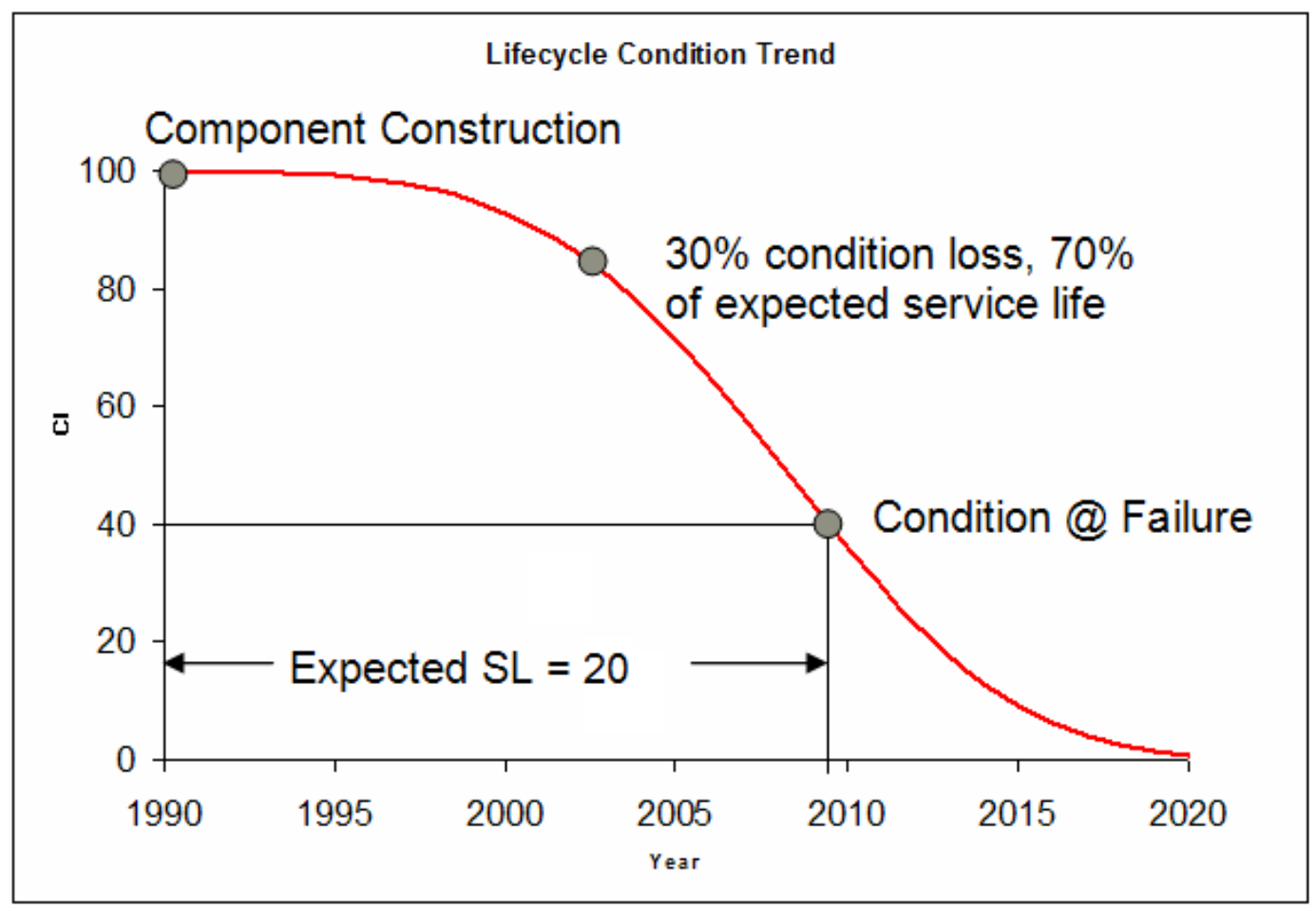

Figure 2. Example initial life-cycle condition trend. 


\subsection{Calibration with inspection information}

The initial model seeding described above is reflective of a typical component-section, but they do not account for the unique reliability or behavior of a specific individual component-section present in a specific building. Therefore, as time progresses and the component-section ages and degrades, it becomes important to assess the component-section condition at various points during the life-cycle to compare and calibrate the expected condition with the actual observed condition.

As the component-section progresses further into its life-cycle and more inspections are performed, these historical inspections form the shape of the observed and projected life-cycle curves. Actual historical condition degradation trends are then used to accurately model the behavior of the component condition and reliability profile. The initial industry average estimate of expected service life is readjusted based on information about how the component is degrading in place. Figure 3 illustrates how collected inspection data are used to readjust the expected service life and lifecycle curve. As more data are added, the better the model becomes tailored and unique for any given component-section. Figure 3 also illustrates how the expected service life shifts.

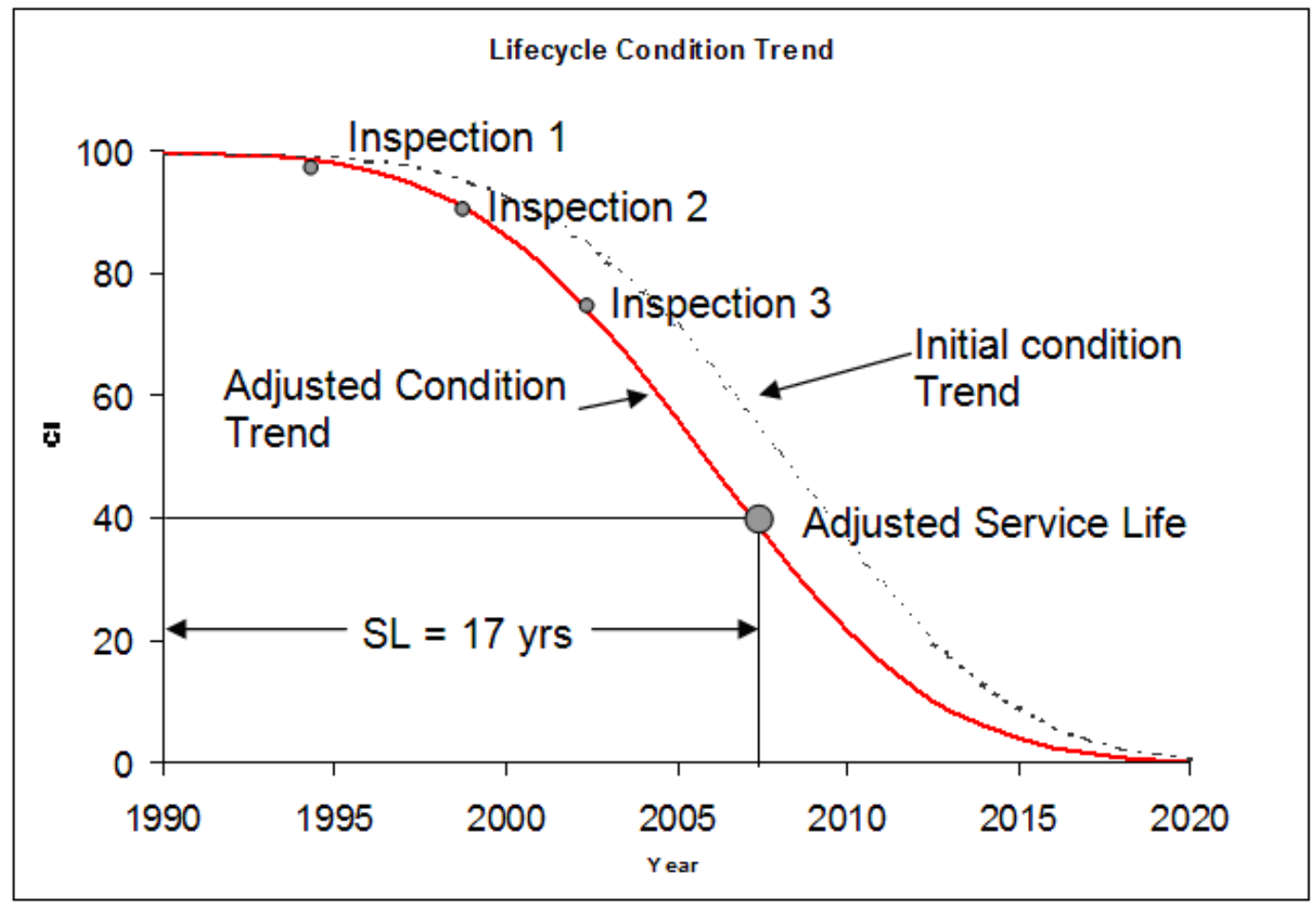

Figure 3. Life-cycle condition trend for component-section after inspection data calibration. 


\subsection{Weighting historical inspection data}

After several inspection points are collected, the model begins to accumulate information about the behavior of the component-section's condition over time. Some inspections and data points are more accurate than others, depending on the inspection type done, the level of inspection detail, and the inspection date. The condition-prediction process takes these factors into account when adjusting the model.

The mathematical Weibull model has only three parameters or degrees of freedom to define the condition life-cycle curve. However, with the initial installation or construction date, the expected service life date, and several inspections collected, more than three data points are available. The model uses regression analysis to fit the prediction curve through data points by minimizing the sum of squares residual error. Each point is also associated with a weighting factor to modify its residual error. The more accurate the data point, the higher the weighting factor and the more effect it has on the adjusted model. Also, the adjusted prediction curve always passes through the last known CI point. Factors affecting the weighting values for a data calibration point include the component-section installation or construction date certainty, the time (in years) since the previous inspections, the type of inspection (distress survey or direct rating), and the change in CI value between inspections.

\subsection{Scheduling inspections}

This proposed model makes clear how important inspection scheduling is in the condition-prediction process. The quantitative BUILDER inspections provide the information for self-correcting the model based on actual conditions. The prediction model is always most accurate in the time near a well-trusted data point, such as in the case of a recent inspection. As time passes and the inspection information becomes dated, the predicted condition becomes less certain. Depending on the predicted condition, the certainty of the predicted value, the consequence of prediction error, or the amount of service calls or trouble tickets will trigger the need to schedule another inspection. This new inspection once again provides data that verifies the model and enables it to self-correct.

The prediction model process provides a way to efficiently schedule inspections and justify their benefits. Since inspections cost money and require personnel resources, performing inspections at selected times in the 
life-cycle, based on need and not the calendar, allocates those resources more effectively.

\subsection{Calibration when work is performed}

In addition to adjusting the condition model based on inspection information, corrective repair work has an effect on the future condition trend. If the projected condition drops below a designated acceptable level or standard, component-section repair or replacement is necessary. If a repair is performed, then the deterioration model experiences a step function increase at the time of repair which raises the CI to an assumed value of 95. Because it cannot scientifically be assumed the component-section has been repaired to a defect-free condition $(\mathrm{CI}=100)$, a reduced $\mathrm{CI}$ is used. However, if a quality control inspection is performed on the new work, then the CI value determined by the inspector (up to 100) is used in the model. To predict the component-section condition trend response after repair, the established pre-repair degradation trend is extended).

When determining the new degradation rate, the model also takes into account the age of the component-section at the time of repair. Generally, the older a component-section is at the time of repair, the faster the postrepair degradation is compared to the pre-repair rate. This difference is evident in the two slopes shown in Figure 4, where the gain decreases as the end of the component-section's service life approaches. 


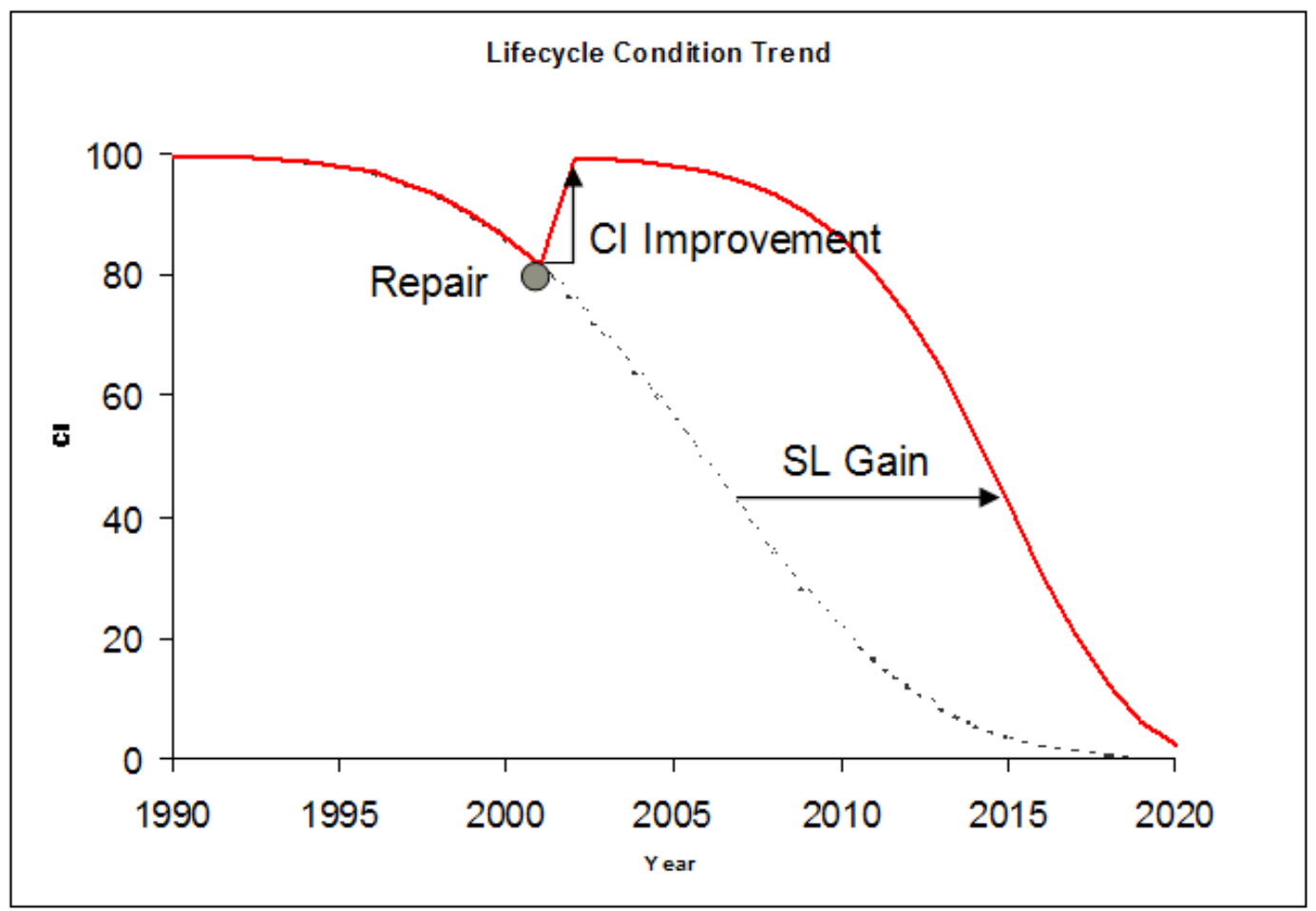

Figure 4. Life-cycle condition trend for component-section after corrective repair.

Multiple repairs cannot extend the life of a component-section indefinitely, so eventually, a component-section replacement is required. Replacement resets the service life clock. From that point, data from inspections performed periodically on the repaired component-section are applied to adjust the life-cycle curve as discussed above.

When the component is replaced with an identical component-section, called replacement in kind, the prediction model uses the characteristics of the replaced component-section's degradation trend to initialize the new component-section condition-prediction model. 


\section{Incorporating ISR-I Condition Rating Information for SRM Planning}

\subsection{Linking ISR-I rating data}

The Army's Installation Status Report for Infrastructure (ISR-I) is how Army installations report the condition and readiness of their infrastructure assets. Building tenants are primarily responsible for providing a condition/ readiness rating based on standardized guidelines that consider several different aspects of the facility. This process results in a general qualitative rating of Green, Amber, or Red for each facility, rolled up by building category code (CATCODE). The ISR-I is inexpensive to implement, but it is also subjective and does not link to actual building component work needs at the tactical (installation) level. While the overall ISR-I process is expected to be the main means of collecting facility rating data for the foreseeable future, the BUILDER system can potentially feed aspects of the ISR-I. For example, HVAC ${ }^{1}$ system condition index values derived from the BUILDER rating process feed the HVAC component of ISRI. This results in a more objective condition rating for these aspects of the facility, while providing a direct linkage to equipment work needs. Based on previous research, the following map (Figure 5) between the BUILDER CI metric and the ISR-I rating was developed.

\begin{tabular}{|c|c|c|}
\hline Condition Index & Descriptor & ISR-I Rating \\
\hline $100-85$ Good & $\begin{array}{l}\text { Slight or no serviceability or reliability } \\
\text { reduction }\end{array}$ & \multirow{2}{*}{ Green } \\
\hline 85-70 Satisfactory & $\begin{array}{l}\text { Serviceability or reliability is degraded but } \\
\text { adequate. }\end{array}$ & \\
\hline 70-55 Fair & $\begin{array}{l}\text { Serviceability or reliability is noticeably } \\
\text { degraded }\end{array}$ & \multirow{2}{*}{ Amber } \\
\hline 55-40 Poor & Significant serviceability or reliability loss. & \\
\hline 40-25 Very Poor & $\begin{array}{l}\text { Unsatisfactory serviceability or reliability } \\
\text { reduction }\end{array}$ & \multirow{3}{*}{ Red } \\
\hline 25-10 Serious & $\begin{array}{l}\text { Extreme serviceability or reliability } \\
\text { reduction }\end{array}$ & \\
\hline 10-0 Failed & Overall degradation is total. & \\
\hline
\end{tabular}

Figure 5. BUILDER condition index mapping to ISR-I rating.

\footnotetext{
1 HVAC: heating, ventilating, and air conditioning.
} 
As ISR-I ratings for each component are sent back to BUILDER, the BUILDER models adjust the expended condition trend based on those actual observations. If the ISR-I rating shows a component in Green status while BUILDER predicts the component as Amber based on age and past history, the BUILDER models will adjust the future condition trend as shown in Figure 6 to reflect the observed condition.

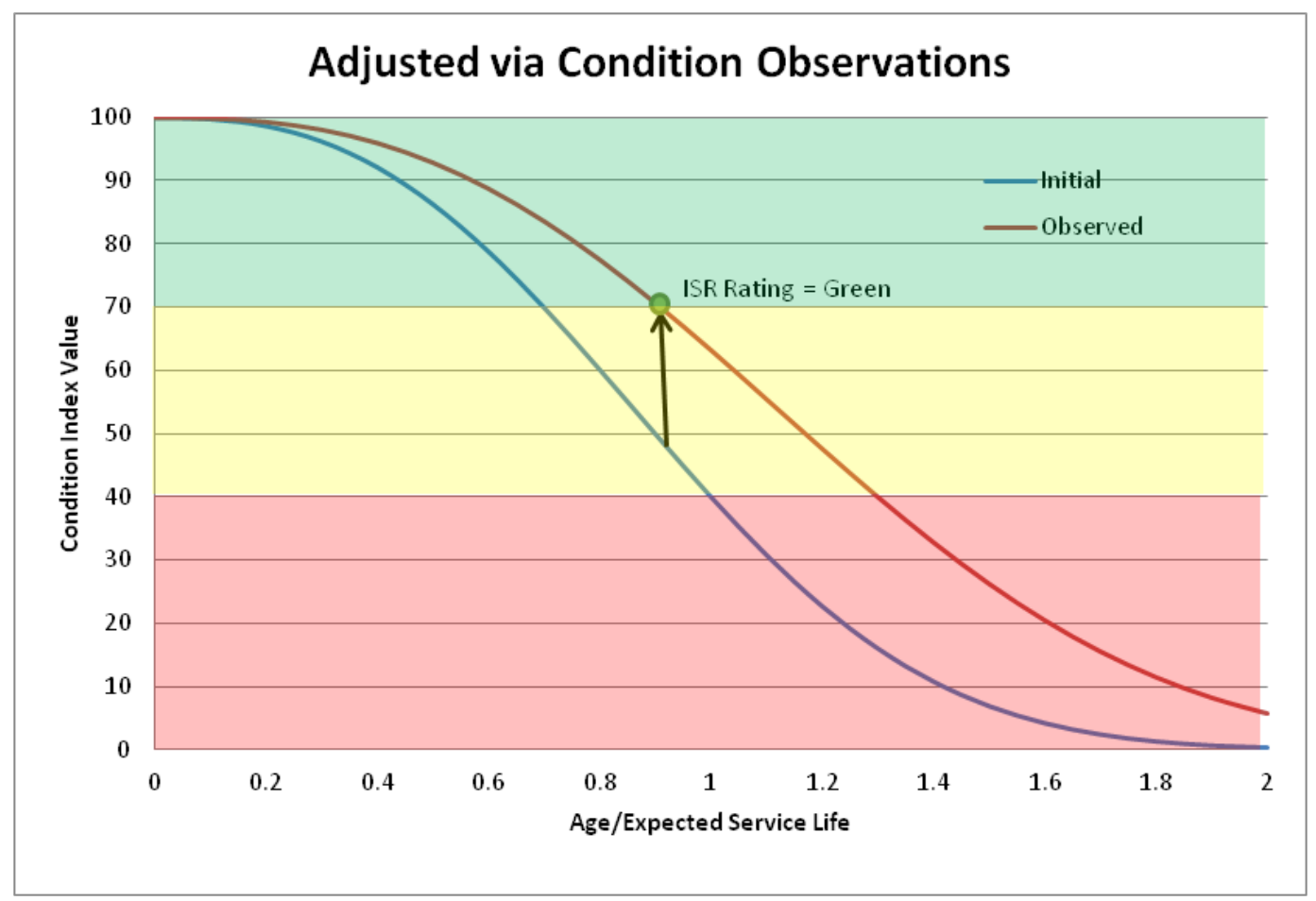

Figure 6. Adjusted condition trend using ISR-I rating information.

\subsection{Use with SRM planning}

This information and prediction capability greatly improves SRM planning potential at the facility level. Figure 7 shows typical facility information for an administrative facility built in 1979 and renovated in 1999 with a plant replacement value (PRV) of $\$ 3,034,000$. System level inventory information consisting of component type, quantity, and year installed is used to define the constituent components of the facility. Each of these components has associated unit replacement costs and expected service life estimates based on construction industry standard data. This inventory information is shown in the Component Level Info section of Figure 7. Based on these data, the age and initial estimated remaining service life (RSL) is determined, and the BUILDER SMS uses this information to calculate an obsolescence index (OI) for each component. The OI is based solely on the age of the building component (using its install year) in relation to the ex- 
pected service life of the component. It is used as a proxy measure of the magnitude of modernization requirements for a facility arising from excessively aged and obsolescent components.

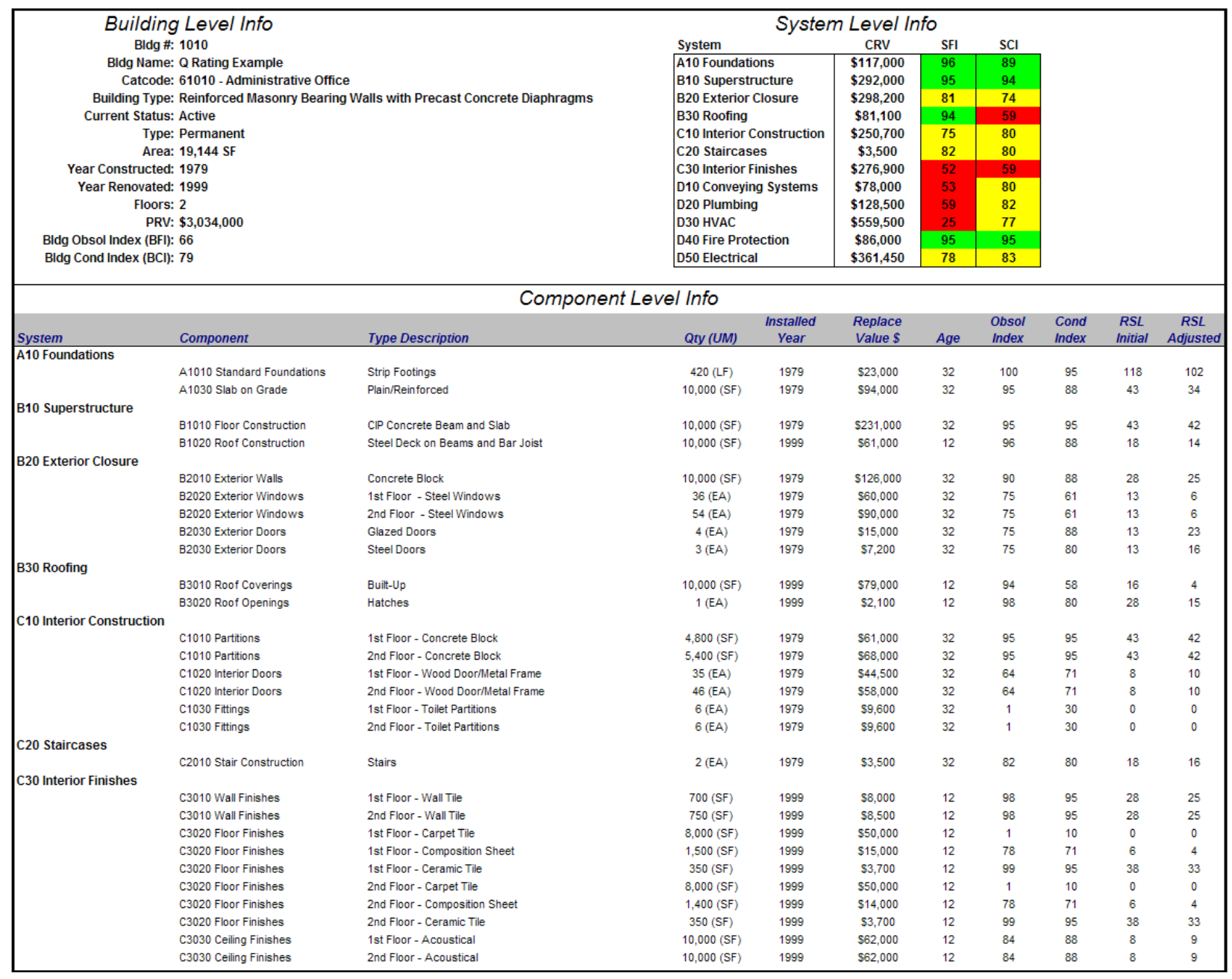

Figure 7. Facility-level SRM planning information.

From this component-level information, major components of the building are identified and classified into systems. Facility assessments, including ISR-I ratings, are used to adjust actual observations for component CI, functionality index (FI), and adjusted RSL. The projected repair or replacement of these individual components (provided the overall system is still in good condition) is considered sustainment.

These component values are then incorporated into the major building system data based on component replacement values (CRVs), as shown in Figure 8. These system level metrics are used to identify restoration and 
modernization (R\&M) facility requirements. Estimates for the cost of these R\&M requirements are based on system-level CRVs.

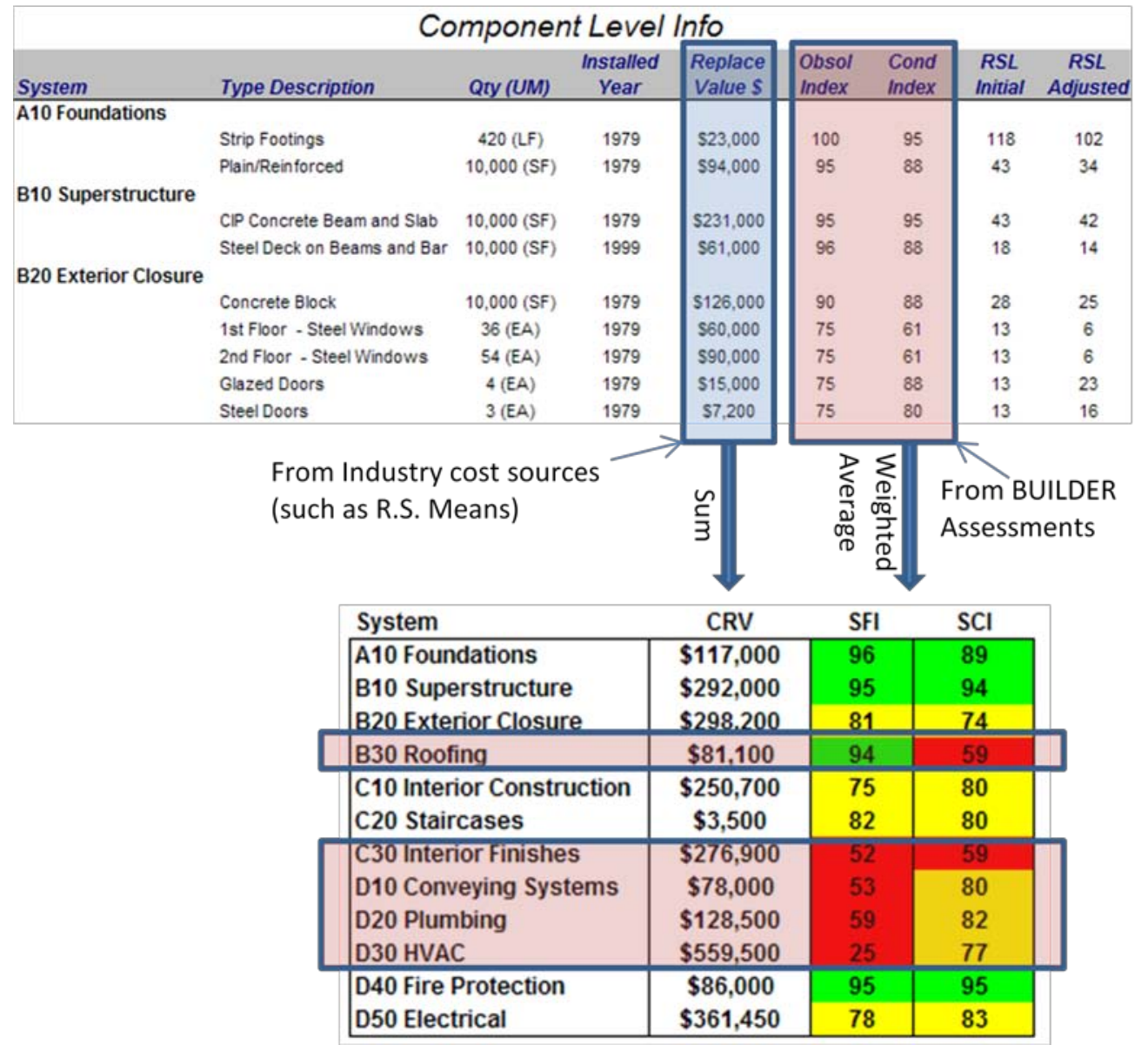

Figure 8. Rollup performance data from component to system level

These data are finally rolled up to the building level. In the Building Level Info section of Figure 7, the resulting Building Functionality Index (BFI) was 66, and the Building Condition Index (BCI) was 79. This shows that while a number of major components and systems are aged and may be obsolete, they have been fairly well maintained from a condition standpoint. The System Level Info section shows a breakdown of system functionality index (SFI) and system condition index (SCI) by major system. Also shown is the sum of the CRVs for all components in that system. The interior finishes, conveying, plumbing, and HVAC systems are all showing low SFI scores, reflecting initial potential candidates for modernization based on age and ISR-I mission functional ratings. It is also important to note that the actual condition index reflected in the SCI scores shows that the conveying, plumbing, and HVAC systems rated higher than might be expected based on age alone while the roofing rated lower. The divergence 
between these two measures might indicate that while the conveying, plumbing, and HVAC systems are fully operational and relatively well maintained (and may remain that way for some time), their excessive age may cause other non-condition issues to affect performance. These issues, such as failing to meet current mission, energy efficiency, and water conservation requirements, are typically addressed through modernization.

From a condition standpoint, there are two systems in this example building that rated as Red, with a total system CRV of $\$ 358,000$ representing potential restoration opportunities, and also a handful of individual components that rated low and represent sustainment requirements. Three additional systems - conveying, plumbing, and HVAC - are rated red based on obsolescence. The combined system CRV for all is $\$ 766,000$. The replacement of these systems represents potential modernization requirements. Table 1 summarizes an example of SRM costs, including actions associated with each.

Table 1. Work classification breakdown.

\begin{tabular}{|l|l|l|}
\hline Work Classification & Requirement (\$k) & Actions \\
\hline Sustainment (PE-78) & $\$ 290$ & $\begin{array}{l}\text { Replace carpet, partitions, ext windows, ext } \\
\text { doors }\end{array}$ \\
\hline Restoration (PE-76) & $\$ 358$ & $\begin{array}{l}\text { Premature roof failure due to lack of } \\
\text { sustainment, replace interior finishes }\end{array}$ \\
\hline Modernization (PE-76) & $\$ 766$ & $\begin{array}{l}\text { Replace/modernize systems with low } \\
\text { Functionality Index, including conveying, } \\
\text { plumbing, HVAC }\end{array}$ \\
\hline
\end{tabular}

It is important to note again that the FI and OI are proxy indicators for building system and component modernization needs based solely on age in relation to normal expected service lives. They do not incorporate actual requirements affecting the functionality of a building facility, such as mission, configuration, code compliance, energy efficiency, water conservation, etc. Instead, the assumption is that aged components will have a higher probability of failing to meet actual facility requirements. The OI can be used to prioritize the further, more detailed investigation of certain facilities or systems via engineering evaluations. However, coupled with ISR-I mission functional ratings, this index is used to determine how the individual facility meets specific requirements in a number of areas, such as location, size and configuration, accessibility, structural/ seismic, antiterrorism and force protection (ATFP), energy efficiency, etc. As a result, if ISR-I functionality rating data are available, the SFI would be adjusted 
based on the results of the evaluation to reflect actual building and system capabilities and configurations.

The value of the above approach over a purely modeled portfolio of assets is that this analysis is based on actual system inventory information and the specific component makeup of the building. In addition, the CI reflects actual observed conditions and remaining service life estimates for each facility. The advantages are (1) more actionable information for facility managers at an installation level to determine courses of action for local SRM investments and (2) more accurate and auditable information at higher programmatic levels based on actual building configurations, components, and observed conditions. 


\section{Summary and Recommendations}

\subsection{Summary}

The measurement and prediction of future facility component condition trends is essential to a reliability-centered building life-cycle management program. Because of the large number of dissimilar components in a building portfolio and the lack of detailed models to describe the response in service of each component, reliable prediction of building condition is very challenging. Current models and industry estimates of component service lives rarely account for the local conditions of use, maintenance, and environmental factors, which limits the accuracy of asset-condition predictions.

The BUILDER degradation-prediction model described here provides a feedback loop to self-correct individual life-cycle trends for a wide variety of building components based on data collected through periodic objective assessments. Corrective repair work performed during the life-cycle of a component-section is factored into the life-cycle trend analysis as well. This reliability/ risk-based condition-prediction model supports optimized planning of (1) inspection resources needed to refine the condition trend as required and (2) repair and recapitalization resources to plan corrective work at the appropriate time in the component-section life cycle.

With a condition-assessment history for each facility component-section, the patented prediction models in BUILDER are used to project facility life-cycle condition and degradation and provide estimates of expected component and system failures over time. From this life-cycle condition information, both short-term and long-range facility plans can be developed. Every year, the BUILDER SMS generates a flexible list of work recommendations based on standards and policies applied across all assets. This practice ensures that the installation maintains facilities at common levels based on mission requirements and available funding.

\subsection{Recommendations}

Using the standardized mapping of data elements common to BUILDER and ISR-I, information collected through the ISR-I inspection provides data that can be used to facilitate a new implementation of BUILDER. 
Specifically, the procedure leverages the ISR-I effort to substantially reduce the initial cost of BUILDER implementation. Basic building information, such as the type, quantity, and year installed for several individual facility components are approximated using the data templates previously developed for this purpose. However, when facility managers and planners require more accurate degradation predictions, more detailed data are needed. Therefore, it is recommended that detailed facility data be collected when a building is nearing consideration for a potential SRM upgrade. This practice would allow for a phased approach to collecting and expanding the asset database, thereby allocating more facility-inspection resources to the most critical stages of a building's life cycle.

After an installation's asset inventory is populated and established, ISR-I condition rating data can be incorporated into the BUILDER database on a recurring basis to build a condition-assessment history for building components. Merging ISR-I data with assessment information collected separately from BUILDER, ROOFER, and other Army-approved systems is recommended to improve the quality of facility data and efficiency of collection.

BUILDER is capable of using data from many Army-standard systems, and its accuracy level improves with each added data source. Armystandard systems that are recommended for future data exchange with BUILDER include Headquarters Installation Inventory System (HQIIS), Army Mapper, Computerized Maintenance Management Systems (CMMS), and General Fund Enterprise Business System (GFEBS). 


\section{References}

ASTM E 1557-02. "Standard Classification for Building Elements - Uniformat II.”

“BUILDER Engineered Management System Fact-Sheet” (ERDC-CERL), Champaign IL, http:// www.cecer.army.mil/td/ tips/product/details.cfm?ID=64.

"Knowledge-Based Condition Assessment Manual for Building Component-Sections", ERDC-CERL, Champaign IL.

Installation Status Report - Infrastructure (2010). Standards Rating Booklet 6, Maintenance Facilities - Unit Readiness.

Installation Status Report - Infrastructure (2010). Standards Rating Booklet 19, Unit Operations Buildings

US Patent 7,058,544, “Knowledge-Based Condition Survey Inspection (KBSCI) Framework and Procedure." Washington, DC: Headquarters, Department of the Army.

Uzarski, D. R., M. N. Grussing, and J . B. Clayton. March 2007. “Knowledge-Based Condition Survey Inspection Concepts." ASCE J ournal of Infrastructure Systems 13(1). http://cedb.asce.org/cgi/WWWdisplay.cgi? 156730. 


\section{Acronyms and Abbreviations}

ACSIM - Assistant Chief of Staff for Installation Management

CI - condition index

CMMS - Computerized Maintenance Management System

DPW - Directorate of Public Works

ERDC-CERL - Engineer Research and Development Center, Construction

Engineering Research Laboratory

FCG - Facility Category Group

FI - functionality index

GFEBS - General Fund Enterprise Business System

GIS - geographic information system

HVAC - heating, ventilation, and air conditioning

HQ - headquarters

HQIIS - Headquarters Installation Information System

ISR-I - Installation Status Report for Infrastructure

IT - information technology

ITTP - Installation Technology Transition Program

LAN - local area network

PRV - plant replacement value

SMS - Sustainment Management System

SRM - Sustainment, Restoration, Modernization

XML - Extensible Markup Language 


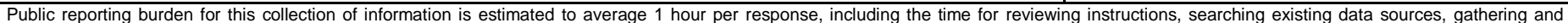

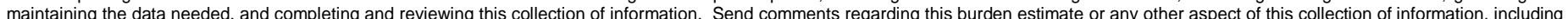

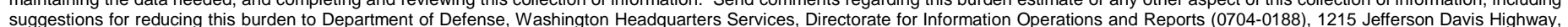

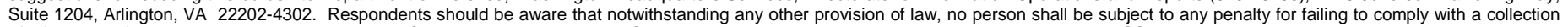
of information if it does not display a currently valid OMB control number. PLEASE DO NOT RETURN YOUR FORM TO THE ABOVE ADDRESS.

\begin{tabular}{l|l} 
1. REPORT DATE (DD-MM-YYYY) & 2. REPORT TYPE
\end{tabular}

September 2012 Final

\section{TITLE AND SUBTITLE}

Facility Degradation and Prediction Models for Sustainment, Restoration, and Modernization (SRM) Planning

3. DATES COVERED (From - To)

5a. CONTRACT NUMBER

5b. GRANT NUMBER

5c. PROGRAM ELEMENT NUMBER

6. AUTHOR(S)

Michael N. Grussing

5d. PROJECT NUMBER

5e. TASK NUMBER

5f. WORK UNIT NUMBER

7. PERFORMING ORGANIZATION NAME(S) AND ADDRESS(ES)

US Army Engineer Research and Development Center

Construction Engineering Research Laboratory

P.O. Box 9005

Champaign, IL 61826-9005

8. PERFORMING ORGANIZATION REPORT NUMBER

ERDC/CERL TR-12-13

9. SPONSORING I MONITORING AGENCY NAME(S) AND ADDRESS(ES)

Office of the Assistant Chief of Staff for Installation Management (ACSIM)

Facilities Branch (DAIM-ODF)

2511 Jefferson Davis Highway

Arlington, VA 22202
10. SPONSOR/MONITOR'S ACRONYM(S) ACSIM

11. SPONSOR/MONITOR'S REPORT NUMBER(S)

\section{DISTRIBUTION / AVAILABILITY STATEMENT}

Approved for public release; distribution is unlimited.

\section{SUPPLEMENTARY NOTES}

\section{ABSTRACT}

This report describes the process for integrating the BUILDER Sustainment Management System (SMS) condition life cycle and prediction analysis capabilities with condition assessment information from the Army Installation Status Report for Infrastructure (ISR-I) program to create BUILDER life-cycle condition models. It expands upon previous efforts to integrate the two systems with a common building component and assessment data framework. This framework is based on the ASTM International UniFormat II classification system elements used to integrate the ISR-I facility components for 63 booklets with BUILDER inventory items.

The framework developed in previous work provides the foundation for comprehensive engineering analysis in support of common system functionality between BUILDER and ISR-I. The Army uses ISR-I data and analysis to determine current requirements for facilities. Prediction capabilities allow for better planning for future requirements. This combination provides comprehensive tools and metrics for program-level prioritization of facility management funds for optimal benefit to Army readiness. Prediction model integration was analyzed under the US Army Installation Technology Transition Program (ITTP). The objectives of this demonstration project were to (1) identify a process to transfer ISR-I condition-rating data to BUILDER and (2) use that condition data to compute life-cycle condition metrics.

\section{SUBJECT TERMS}

BUILDER Sustainment Management System (SMS), prediction models, facility life cycle, condition assessment

\section{SECURITY CLASSIFICATION OF:}

\section{a. REPORT}

Unclassified

\section{b. ABSTRACT}

Unclassified c. THIS PAGE

Unclassified
17. LIMITATION OF ABSTRACT

\section{NUMBER OF PAGES}

32

\section{9a. NAME OF RESPONSIBLE} PERSON

19b. TELEPHONE NUMBER (include area code) 